\title{
A EDUCAÇÃO BILÍNGUE PARA CRIANÇAS SURDAS: SURDEZ COMO EXPERIÊNCIA E INFÂNCIA COMO POTÊNCIA
}

\author{
Bilingual education for deaf children: deafness as an experience and childhood as a \\ potency
}

\begin{abstract}
La educación bilingue para niños surdos: sordera como experiencia e infancia como potencia
\end{abstract}

Lucyenne Matos da Costa Vieira-Machado*

Keila Cardoso Teixeira*

\begin{abstract}
Resumo
Este artigo tem como objetivo discutir sobre a educação bilíngue para crianças surdas a partir de uma aposta: olharmos para a surdez enquanto experiência e para a infância como potência. A educação bilíngue ocupa lugar de destaque no debate de como lidar com a diferença linguística e cultural dos surdos, servindo como bandeira de luta da comunidade surda brasileira e merecendo, portanto, nossa especial atenção. Esta pesquisa trata-se de um estudo de caso em um Centro Municipal de Educação Infantil, no município de Vitória, no Estado do Espírito Santo, sendo esta escola referência em educação bilíngue para surdos no projeto maior do município. Assim, modificamos a linguagem da educação e, consequentemente, a educação bilíngue como um desejo de realidade para crianças surdas na educação infantil. Destacamos que a política bilíngue representa mais do que a utilização de uma língua, ela deve possibilitar aos estudantes surdos espaços educacionais que os levem a provocar o pensamento, estimulando suas capacidades. Deve considerar uma política educacional que respeite a singularidade linguística, revelada mediante a coletividade, a partir de outras pessoas com surdez. $\mathrm{Ou}$ seja, é necessário proporcionar espaços que contribua para que as crianças surdas tenham contato com seus pares linguísticos.
\end{abstract}

PALAVRAS-CHAVE: Educação Bilíngue. Surdez. Infância.

\begin{abstract}
This article aims to discuss about bilingual education for deaf children through the challenge of: outlook deafness as an experience and childhood as a potency. Bilingual education centers the discussions regarding how to deal with the deaf people cultural and linguistic differences, serving as a fighting banner for the Brazilian deaf community, therefore, meriting special attention. The research embodies a case study that took place at the Municipal Center of Child Education located in Vitória, a city in the state of Espírito Santo. The Center, considered as a leading school of bilingual education for the deaf, integrates a bigger project carried in the city. Thus, we understand the educational language

\footnotetext{
* Doutora em Educação pelo Programa de Pós-Graduação em Educação da Universidade Federal do Espírito Santo (PPGE- UFES). Professora e orientadora do curso de Pós-graduação em Educação (PPGE/UFES) e professora colaboradora no programa de pós-Graduação em Linguística (PPGEL). Coordenadora do Grupo Interinstitucional de Pesquisa em Libras e Educação de surdos (GIPLES/Cnpq/UFES). E-mail: lumatosvieiramachado@gmail.com.

* Doutora em Educação pelo Programa de Pós-Graduação em Educação da Universidade Federal do Espírito Santo (PPGE-UFES). Professora adjunta do Departamento de Linguagens, Cultura e Educação/DLCE, Centro de Educação da Universidade Federal do Espírito Santo. Vice-líder do Grupo de Pesquisa em Libras e Educação de surdos (GIPLES/Cnpq/UFES). E-mail: keilakteixeira@gmail.com.
} 
and, accordingly, the bilingual education, as a wish to come true for the deaf children enrolled in Nursery Education. We highlight that the bilingual politic represents more than just the use of two languages. It must ensure to deaf students, educational spaces that evoke thinking and spur their capabilities. It is must also contemplate an education politic that respects the linguistic uniqueness, revealed upon the collectivity that emerges from the relation among the deaf. In other words, it is necessary to provide spaces that contribute for the deaf children to be in touch with their linguistic peers.

KEYWORDS: Bilingual Education. Deafness. Childhood.

\section{Resumen}

Este trabajo tiene como objetivo discutir sobre la educación bilingüe para niños sordos a partir de una postura: mirar la sordera como experiencia y la infancia como potencia. La educación bilingüe ocupa un lugar predominante en el debate sobre cómo afrontar la diferencia lingüística y cultural de los sordos, sirviendo como bandera de lucha de la comunidad surda brasileña y mereciendo, por tanto, nuestra especial atención. Esta investigación expone un estudio de caso en un Centro Municipal de Educación Infantil, en el municipio de Vitória en el Estado de Espírito Santo que es una escuela de referencia en educación bilingüe para sordos del proyecto mayor del municipio. Así modificamos el lenguaje de la educación y por consiguiente la educación bilingüe como un deseo de realidad para niños sordos en la educación infantil. Destacamos que la política bilingüe representa más de lo que la utilización de una lengua, esta debe posibilitar a los estudiantes sordos espacios educacionales que lo lleven a provocar el pensamiento, estimulando sus capacidades. Debe considerar una política educacional que respete la singularidad lingüística, revelada mediante la colectividad, a partir de otras personas con sordera. $\mathrm{O}$ sea, es necesario proporcionar espacios que contribuyan para que los niños sordos tengan contacto con sus pares lingüísticos.

PALABRAS CLAVE: Educación Bilingüe. Sordera. Infancia.

\section{INTRODUÇÃO}

\section{Sobre uma aposta: à guisa de introdução}

Iniciamos nosso texto esclarecendo nosso olhar e fazendo uma aposta: de que ao olharmos para a surdez enquanto experiência e para a infância como potência, modificamos a linguagem da educação (BIESTA, 2014) e, consequentemente, a educação bilíngue como um desejo de realidade (LARROSA, 2008) para crianças surdas na educação infantil.

Pela via da linguagem é possível revermos nossa posição e para defendermos nossa aposta, tomamos por referência as práticas $^{1}$ na educação infantil na formação de um espaço pedagógico (MASSCHELEIN; SIMONS, 20014) entre professores regentes e professores especialistas em educação bilíngue, e por fim, problematizamos sobre qual é o papel da instituição escolar no trabalho colaborativo junto aos pais das crianças surdas, professores e instâncias administrativas.

Olhar a surdez como experiência nos possibilita avançar para além da materialidade do corpo e potencialmente das marcas de normalização que o constituem. Partimos da ideia geral

\footnotetext{
${ }^{1}$ Partimos das teorizações foucaultianas para definirmos práticas como uma racionalidade ou regularidade que organiza o que os sujeitos fazem quando falam ou quando agem, constituindo uma experiência ou um pensamento (CASTRO, 2009).
} 
de que o ser é produzido na linguagem, logo, a surdez não se trata aqui de uma representação exterior de um sujeito, mas uma invenção do nosso tempo. Conforme Lopes:

Para além da materialidade do corpo, construímos culturalmente a surdez dentro de distintas narrativas associadas e produzidas no interior (mas não fechadas em si mesmas) de campos discursivos distintos-clínicos, linguísticos, religiosos, educacionais, jurídicos, filosóficos etc. (LOPES, 2007, p.7).

Assim, na esteira de Foucault, olhar a surdez como matriz de experiência é segundo Witchs e Lopes possibilitar que seja "[...] entendida como uma forma de constituir sujeitos surdos, subjetividades surdas, modos bem específicos de ser e de se relacionar em um mundo regulado por normas audistas". (WITCHS; LOPES, 2015, p. 36). Segundo os autores, para afirmarmos a surdez como uma experiência, é preciso entender que Foucault procurou analisar o que chamou de focos ou matrizes de experiência a partir da correlação de três eixos que a constituem: "o eixo da formação dos saberes, o eixo da normatividade dos comportamentos e, enfim, o eixo da constituição dos modos de ser do sujeito" (FOUCAULT, 2010, p. 41).

E o olhar para a infância como potência que propomos aqui traz à tona a discussão de Masschelein e Simons a respeito da infância como potência de vida na construção de um espaço pedagógico/institucional. Segundo os autores, é possível entender a infância como uma potencialidade ou uma potência. Seria uma espécie de "vácuo que afasta o aluno de tudo aquilo que, como inteligibilidade, a ele se integra, isto é, de tudo que o representa na ordem da realidade e da compreensão" (MASSCHELEIN; SIMONS, 2014, p. 34).

Encontramos em Biesta uma análise sobre a questão da formação, e aqui fazemos o nosso recorte de professores. O autor afirma que um profissional bem formado defende que para se ter uma educação democrática e um futuro humano é necessária uma prática pedagógica "para além da aprendizagem". Ao falar de educação, seja na discursividade da educação de crianças, na educação de adultos, ou de qualquer modalidade, esta deve ser entendida como uma intervenção na vida de alguém e deve ser motivada pela ideia de tornar a vida melhor, e portanto, mais completa. Nesse aspecto, Biesta comenta:

\begin{abstract}
Muitas práticas educacionais são configuradas como práticas de socialização. Preocupam-se com a inserção dos recém-chegados numa ordem sociopolítica e cultural existente. Isso tem sua importância, porque equipar os recém-chegados com as ferramentas culturais necessárias para a participação numa forma particular de vida e, ao mesmo tempo, assegura a continuidade cultural e social. Mas não podemos ser demasiado ingênuos a esse respeito, porque esses processos também contribuem para a reprodução de desigualdades existentes. - involuntariamente ou, naqueles casos em que a educação é utilizada para conservar determinadas práticas e tradições, também voluntariamente (BIESTA, 2013, p. 16).
\end{abstract}

Para desenvolvermos nossa análise sobre a educação bilíngue para crianças surdas matriculadas em uma instituição de educação infantil, elegemos como lócus o CMEI Mafalda, situado em Vitória/ES, referência na educação bilíngue. Participaram desta investigação uma professora bilíngue, uma professora surda e duas professoras regentes. Como instrumento metodológico, recorremos a observações participantes e entrevistas abertas com os participantes. Suas narrativas foram importantes para compreendermos como entendem e realizam a educação bilíngue para as crianças surdas na referida instituição. Para este artigo, vamos focalizar nas análises das práticas cotidianas do CMEI a partir das observações participantes $^{2}$.

\footnotetext{
${ }^{2}$ A pesquisa completa pode ser encontrada na tese de doutorado intitulada: A criança surda na educação infantil: contribuições para pensar a educação bilíngue e o atendimento educacional especializado. Fonte: TEIXEIRA, Keila Cardoso. A criança surda na educação infantil: contribuições para pensar a educação bilíngue
} 
Conforme as percepções das vivências durante a pesquisa de campo e as leituras das observações e entrevistas realizadas, de modo geral, tecemos considerações acerca do cotidiano e da rotina da escola em relação à proposta inclusiva; discutimos como os planejamentos e práticas pedagógicas são constituídos e desenvolvidos por professores regentes e professores especialistas em relação à educação bilíngue; e por fim, problematizamos sobre qual é o papel da instituição no trabalho colaborativo junto aos pais das crianças surdas, professores e instâncias administrativas.

Diante do exposto, nosso artigo, além da discussão sobre as práticas na educação bilíngue como potência na educação dos surdos, trata a infância como potência na constituição de um espaço pedagógico.

\section{A infância da criança surda como espaço de correção e potência}

Segundo Vieira-Machado e Victor (2015), a infância da criança surda como tempo pré-existente era e ainda é considerada a melhor fase para "tratar" a "doença" surdez. Pesquisas e estatísticas apontam para a educação precoce como a melhor possibilidade de instalação das tecnologias que são criadas para adequar o corpo surdo.

A infância cronológica da criança surda é alvo da Medicina desde o seu nascimento. Por isso, tão logo a família recebe o diagnóstico dessa criança, geralmente dada por um médico, o profissional da área de Fonoaudiologia entra imediatamente para, como forma de superar a decepção da notícia, lançar mão de todas as tecnologias disponíveis e possíveis para que a criança surda possa de alguma forma ser mais parecida com as pessoas ouvintes.

Porém, neste texto, propomos olhar para a infância enquanto potência e, a partir disso, analisar as práticas escolares como formas de produção de um espaço pedagógico na tecitura de um desejo de realidade.

Segundo Masschelein e Simons, é possível entender a infância como uma potencialidade, ou uma potência e na capacidade de ex-posição. Seria uma espécie de "vácuo que afasta o aluno de tudo aquilo que, como inteligibilidade, a ele se integra, isto é, de tudo que o representa na ordem da realidade e da compreensão" (MASSCHELEIN; SIMONS, 2014, p. 34).

No que concerne a infância enquanto potência, os autores a conceituam a partir de uma tríplice potência: a potência do movimento ou do deslocamento para fora de si, a potência da palavra ou da tradução e a potência da reminiscência, ou da capacidade de recordar-se de si, do pensamento.

O grande desafio aqui é olhar para as práticas como construção de um espaço pedagógico bilíngue no sentido que dá os autores, uma vez que para desenvolvermos essa noção de infância, temos que nos afastar muitas vezes do próprio lugar comum da educação especial.

Um outro desafio que nos empreendemos aqui é olhar para a educação bilíngue como construção de um desejo de realidade. Para Larrosa (2008) o desejo de realidade é a própria pulsão de vida, o desejo ou a vontade de realidade que tem relação com a suspeita de que falta algo. Todo nosso empreendimento metodológico passa por problematizar a educação bilíngue como uma grande possibilidade de construção de um espaço pedagógico em que tempos e práticas são construídos no desejo de fazer emergir a potência e a capacidade de ex-posição.

e o atendimento educacional especializado. Programa de Pós-Graduação em Educação, PPGE, UFES. Tese de doutorado, 2016, $216 \mathrm{f}$.) 
Imbuídas desse desejo em nossas análises, o que propomos aqui é “[...] fazer vibrar esse desejo de investigação educativa, porque talvez esse desejo de realidade nos impulsione a problematizar as nossas formas de ver, dizer e de pensar 'o educativo"” (LARROSA, 2008, p. 186).

Para desenvolvermos as análises a que nos propomos, esta pesquisa trata-se de um estudo de caso de um Centro Municipal de Educação Infantil (CMEI), no município de Vitória, no Estado do Espírito Santo cujo nome fictício é Mafalda. Este espaço atende crianças de 01 a 05 anos de idade. No período da investigação, estavam matriculadas 2 crianças surdas, com idades entre 2 e 4 anos. As crianças surdas matriculadas frequentavam a sala de atividade regular em um turno e apenas uma frequentava o Atendimento Educacional Especializado (AEE) no contraturno. Dessa forma, uma permanência na instituição até às 17 horas. Este CMEI tratava-se de uma escola referência na educação bilíngue.

Em 2008, o município de Vitória implanta um projeto educacional bilíngue, intitulado "EDUCAÇÃO BILÍNGÜE: ressignificando o processo socioeducacional dos alunos com surdez, no Sistema Municipal de Ensino de Vitória, por meio do ensino, uso e difusão da LIBRAS". Esse projeto aponta para o respeito à singularidade linguística e o contato com seus pares usuários da língua de sinais, mergulhando assim no fluxo da comunicação e despertar a consciência de sua identidade surda (PMV/SEME, 2008 p. 5).

Nessa direção, nove escolas referências para matrículas de estudantes surdos são organizadas, sendo sete escolas de Ensino Fundamental e duas de Educação Infantil. Essas escolas são estrategicamente localizadas dentro do município, já que até o ano de 2007 os estudantes surdos encontravam-se matriculados em diversas instituições, sem a garantia do atendimento educacional comum e especializado (PMV/SEME, 2008 p. 6).

Para garantir esse atendimento na sala de aula comum e no AEE, o município cria espaços/tempos escolares e quatro novos cargos: professor de Libras, instrutor de Libras, professor bilíngue e tradutor e intérprete de Libras. Desta forma, o município afirma, como objetivo desse projeto, a garantia e respeito à experiência visual e linguística do estudante surdo no seu processo de ensino-aprendizagem, utilizando a LIBRAS e a Língua Portuguesa escrita como segunda língua, resguardado o direito de opção da família ou do próprio aluno pela modalidade oral da Língua Portuguesa (PMV/SEME, 2008 p. 6).

Nessa direção, com a implementação desse projeto, o município também organizou formas de atendimentos, conforme legislações específicas, com ações tanto para a inclusão do aluno surdo na sala de aula comum como também para o Atendimento Educacional Especializado (AEE). Nesse contexto, a política pública educacional do município de Vitória tem procurado enfatizar e respeitar o aluno surdo, garantindo a ele, nesse movimento de inclusão, não apenas o acesso, mas também a permanência com qualidade educacional.

Para compreender de que forma a inclusão da criança surda nesta instituição ocorria, optamos por detalhar a organização da instituição de educação infantil para nela identificarmos pistas de uma proposta inclusiva e bilíngue. Definimos alguns pontos relevantes, a saber: a) linguagem visual do espaço, b) aspectos cronológicos, c) aspectos pedagógicos e d) as atividades especializadas.

\section{Educação bilíngue para além da expectativa tecnológica}

Uma das maiores ciladas que devemos nos precaver é a transformação da educação bilíngue em práticas tecnológicas específicas e não voltadas para a produção de um espaço pedagógico no sentido que dá Masschelein e Simons (2014). Dependendo da forma como a 
surdez é inscrita discursivamente nos diferentes espaços, a infância como potência pode se perder de vista.

Analisar uma educação bilíngue de surdos em instituições como afirma Lacerda e Santos (2013) implica pensar em modos múltiplos de organização escolar, de composição de equipes de trabalho, de gestão administrativa e financeira, de espaços pedagógicos e de propostas educacionais, de lutas e de conquistas nos/dos estabelecimentos de ensino. Além disso, descrever e projetar escolas bilíngues de surdos está ligado ao que se entende por educação e por bilinguismo, ou seja, apesar da criação de algumas propostas semelhantes de escola, há outros fatores que vão compondo um currículo escolar.

Inicialmente, chamou-nos a atenção a linguagem visual na identificação dos espaços escolares. Lembramos que a instituição tem essa organização haja vista que é uma instituição referência em educação bilíngue no município.

Assim, deparamo-nos com uma instituição toda sinalizada: portas das salas, banheiros, refeitório, secretaria, salas de aulas especializadas (informática e artes). As salas onde as crianças surdas estão matriculadas tem uma sinalização diferenciada. Com painéis e cartazes com sinais (cores, rotina, alfabeto, números) das atividades desenvolvidas por elas e professores. A partir dessa sinalização, percebemos uma atitude tecnológica muito comum em escolas referência em educação bilíngue no município de Vitória. Não é diferente no CMEI pesquisado.

O grande perigo está em associar a sinalização a uma única forma de identificar o bilinguismo na escola. A Libras como tecnologia e não como língua de vida é um grande entrave na produção de um espaço pedagógico com as crianças surdas a fim de olhá-las como seres de palavra.

Segundo Biesta "a principal pressuposição por trás de uma atitude tecnológica é a ideia de que a educação é um instrumento que pode ser posto a funcionar para produzir certos objetivos pré-determinados" (BIESTA, 2013, p. 102). Assim, corremos o risco de a Língua de Sinais se tornar uma técnica ou uma estratégia educacional e perder a dimensão de uma discussão crítica sobre os objetivos de fato da educação bilíngue para surdos ${ }^{3}$.

Quanto aos aspectos cronológicos da instituição, observamos um certo zelo na distribuição das práticas entre cuidar e educar. Os tempos de alimentação, higienização e descanso não se sobreponham aos tempos de atividades lúdicas e pedagógicas cujos objetivos pareciam estar alinhados com o planejamento pedagógico da instituição.

No período que a pesquisa foi realizada, a instituição atendia duas crianças com idades diferentes e contato com a língua de sinais também diferentes. Essa rotina parecia indicar o respeito a essas especificidades ao não se concentrar somente no cuidar, preocupando-se, sobretudo, com o educar e a apropriação do conhecimento. Por isso, ao elaborar os planos de trabalhos individuais, os momentos, tempos e espaços eram problematizados, visando o desenvolvimento dos objetivos.

Nessa direção, as atividades eram distribuídas ao longo da tarde e manhã, nas situações lúdicas de brincadeiras, atividades de registro, contação de histórias, atividades psicomotoras e artísticas. Do mesmo modo que eram respeitados os horários de alimentação, higienização e descanso.

\footnotetext{
${ }^{3}$ Segundo Vieira-Machado e Lopes (2016) a institucionalização da educação bilíngue para surdos no Brasil se dá com a emergência da legislação específica sobre a Libras (Lei 10.436/2002 e Decreto 5626/2005). Vale ressaltar que essa legislação específica é resultado de anos de luta da militância surda por essa realidade.
} 
Sobre os aspectos pedagógicos, observamos uma preocupação em se garantir a participação e aprendizagem das crianças surdas. Para tanto, as atividades planejadas pelas professoras regentes eram discutidas com a equipe bilíngue, com o objetivo de as crianças acompanharem de acordo com seus ritmos, condições, conhecimentos e desenvolvimento das situações pedagógicas vivenciadas por elas na sala de atividades, no trabalho conjunto em algumas das práticas do AEE e nos momentos de oficina de Libras com toda turma.

Já as atividades especializadas, podemos afirmar como sendo uma nova configuração de rotina na vida escolar da criança surda. Esse foi um espaço onde constatamos a presença mais efetiva das profissionais bilíngues, com a instrutora surda e a professora bilíngue no processo educacional do estudante. Elas são responsáveis, nesse momento, pelas propostas de confeccionar materiais didáticos e pedagógicos acessíveis, levando em conta as necessidades educacionais específicas dos estudantes surdos, público-alvo da Educação Especial e os desafios que eles vivenciam no ensino comum, a partir dos objetivos e das atividades propostas no currículo.

O AEE torna possível a esses profissionais trazerem propostas novas de atividades e também trabalhar os conteúdos abordados no currículo da instituição. Outra questão que favorece o AEE é a língua de sinais, que transita o tempo todo nesse local. Já na sala de atividades, a criança ficava, na maioria das vezes, sem esse profissional, estando sob a responsabilidade da professora bilíngue. Porém, é importante destacar que a equipe quando era solicitada sempre se fazia presente participando das atividades nas duas salas em que haviam crianças surdas matriculadas; o profissional ia à sala da criança e fazia a intervenção pedagógica nesse espaço.

A criação de espaços pedagógicos visa a produção de potências. Segundo Larrosa "o sujeito da experiência é um sujeito ex-posto, ou seja, receptivo, aberto, sensível e vulnerável" (LARROSA, 2008, p. 187). O espaço pedagógico produzido prevê o ser de palavra que é o sujeito surdo. Ao compartilhar a Libras com as outras crianças, potencializa a interação entre elas e a compreensão.

Mas o que significa seres de palavras? Significa dizer que são seres falantes, mas sobretudo e antes de qualquer outra coisa, que uma palavra humana lhe foi endereçada, a qual querem reconhecer e à qual querem responder [...] na condição de homens. Assim pode-se dizer que a infância como vácuo implica uma carga (ou uma dívida) de resposta. Ademais, um ser de palavra está exposto ao outro e às palavras dos outros. [...] e que só é possível falar de alguma coisa, falando a alguém. (MASSCHELEIN; SIMONS, 2014, p. 35).

Vale ressaltar que a política bilíngue representa mais do que a utilização de uma língua, ela deve possibilitar aos estudantes surdos espaços educacionais que o levem a provocar o pensamento, estimulando suas capacidades. Deve considerar uma política educacional que respeite a singularidade linguística, revelada mediante a coletividade, a partir de outras pessoas com surdez. Ou seja, é necessário proporcionar espaços que contribua para que as crianças surdas tenham contato com seus pares linguísticos.

Nesse sentido, ressaltamos que em se tratando de crianças surdas, que não se apropriaram da língua de sinais nas relações cotidianas e começam a frequentar a instituição, que é o lugar do aprendizado sistemático e intencional, o ensino e a aprendizagem dessas duas línguas se confundem. Ora acontece nas conversas espontâneas ora nos momentos de ensino. A Língua de Sinais corre sério risco de se tornar uma tecnologia, no sentido que dá Biesta (2013) e não uma língua viva.

Tomamos aqui uma precaução. Ao tornar a Libras a língua da escola, corremos sério risco de tirar dela a possibilidade de ser uma língua materna (a língua da casa) e torná-la uma língua paterna (língua do Estado). Segundo Masschelein e Simons (2017) devemos abordar a 
questão da língua para além das questões políticas de seu uso, mas em uma perspectiva pedagógica. Não se deve desconsiderar a política nas questões que envolvem a língua, mas cuidar para que a Libras não fique tutelada no uso dela nos espaços escolares. A tutela pedagógica é um risco ao uso comum da língua. O grande risco que os autores nos colocam é: seu uso pode ser emancipador ou alienante.

Assim, podemos inferir que toda criança surda, independentemente da idade e do grau de domínio da língua de sinais, pode ser sujeito das suas experiências e produtora de conversas em língua de sinais, desde que haja uma mediação de qualidade e que sejam criadas as condições necessárias para essa produção, reconhecendo que a possibilidade de comunicação não está no aparato biológico e nem depende da idade, mas funda-se nas relações dialógicas entre os seres humanos e deve fazer parte do processo de ensino e aprendizagem. Ou seja, são seres de palavra.

\section{CONSIDERAÇÕES FINAIS}

Longe de encerrar a discussão, retomamos aqui a nossa aposta. A partir dos dados da pesquisa de doutorado, olhamos para as práticas vividas cotidianamente na escola como possibilidade de criar uma outra linguagem para a educação no sentido que dá Biesta (2013) quando buscamos olhar para a surdez enquanto experiência e para a infância como potência. Assim, possibilitamos que a educação bilíngue pudesse sair do campo do puro desejo para se tornar realidade.

Levando em consideração que pensamos a educação como algo difícil, nos termos de Biesta (2013), podemos refletir que, se temos os indícios e partimos da ideia de que a criança surda é um sujeito de palavra, essa outra linguagem para a educação bilíngue deve levar em conta três aspectos: 1) confiança (sem fundamento); 2) violência transcendental e 3) responsabilidade (sem conhecimento).

Segundo o autor, um dos elementos constituintes da relação educacional é a confiança. Vale ressaltar que o risco e a confiança estão ligados basicamente porque a confiança gira em torno daquelas situações em que não se sabe e não se pode saber o que vai acontecer. Por isso, a confiança é sem fundamento, pois se soubéssemos o que iria acontecer não seria confiança. "Sugerir que a educação deve ser livre de risco, que os aprendentes não correm nenhum risco ou que os resultados da aprendizagem podem ser conhecidos ou especificados de antemão é uma representação errônea daquilo que consiste a educação" (BIESTA, 2013, p. 45).

O segundo conceito do autor, trata-se da violência transcedental no sentido derridiano. Podemos ler esse aspecto pela ideia da aprendizagem como resposta e não como apropriação do que desejamos. A aprendizagem como resposta consiste em mostrar quem você é e em que posição está. Consiste em vir ao mundo (BIESTA, 2013). Os professores têm uma tarefa fundamental: criar oportunidades para que os estudantes venham ao mundo e que possam responder como seres de palavra que são. E para isso, o professor deve desafiar os alunos a responderem e esperar a resposta.

"Podemos considerar a aprendizagem como uma resposta ao que é o outro e diferente ao que nos desafia, irrita e até perturba em vez de como aquisição de algo que desejamos possuir" (BIESTA, 2013, p. 47). Assim, a aprendizagem como resposta consiste em mostrar quem é você e em que posição está ao vir ao mundo. Isso é posicionar o sujeito que está aprendendo no lugar do sujeito de palavra. Considerando que a educação é difícil, a resposta aos desafios do professor também não é simples. Então é importante reconhecer que essas relações não são necessariamente fáceis e agradáveis, e que, ao propor questões difíceis que permitem aos estudantes virem ao mundo, desafiamos e possivelmente perturbamos quem 
nossos estudantes são e onde estão e que essa educação acarreta uma violação da soberania do estudante. Derrida se refere a essa violação como violência transcendental.

E por fim, segundo Biesta (2013), se a educação consiste em criar oportunidades para que os estudantes venham ao mundo, e se consiste em propor as questões difíceis que tornam isso possível, fica claro que o terceiro elemento é a responsabilidade (sem conhecimentos). A primeira responsabilidade do educador é pela subjetividade do estudante como um ser singular e único. Pertencentes a própria estrutura da responsabilidade, não conhecemos aquilo pelo que assumimos. Ser um professor, um educador, implica, portanto, a responsabilidade por alguma coisa que não conhecemos, por alguém que não podemos conhecer. Simplesmente ao ser educador assumimos a responsabilidade.

Convidamos os leitores a olharem para a proposta de educação bilíngue para sujeitos surdos por meio de outros aspectos que fogem do simples: "duas línguas". Olhar para a educação bilíngue como a possibilidade de construção de uma outra forma de relação com os sujeitos surdos e com as línguas, tanto a Libras quanto a Língua Portuguesa. Entender que quando escolhemos observar a surdez como experiência e não como uma materialidade do corpo e para a infância enquanto potência e não apenas como um tempo para a correção, acreditamos no ser de palavra que é a criança surda. Em um ser que é capaz de dar uma resposta.

E assim, a educação bilíngue pode se dar na constituição de um espaço pedagógico onde a tríplice potência e a capacidade de exposição dão à criança surda a possibilidade de que a língua a emancipe e não a aliene. E assim, a educação bilíngue como um desejo de realidade cumpre sua responsabilidade com as subjetividades desses sujeitos.

Não podemos afirmar que chegamos a conclusões, que sabemos definitivamente algo sobre a surdez, porque "cada sujeito entra no fluxo das enunciações do grupo social a que pertence, se apropria e transforma a voz do outro (negando-a, subvertendo-a, assumindo-a, reproduzindo-a" (SOUZA, 1998, p. 206). Tentamos compreender as políticas que instituíram esse espaço e, para isso, questionamos o que tem sido proposto. Juntamos a outros saberes e práticas, algumas práticas que nos interpelam, que interpelam o que vem acontecendo, de modo a nos fazer parar e refletir sobre o instituído e o idealizado.

Destacamos, neste estudo, em especial, as discussões e reflexões sobre o papel das relações sociais, da linguagem na constituição da subjetividade, tomando esses elementos como desencadeadores e indicativos da aprendizagem e do desenvolvimento infantil.

Não temos a pretensão de resolver problemas, tampouco postular verdades e apontar responsáveis, mas analisar o presente, destrinchar o que está posto, identificar possibilidades e trazer as tensões presentes nesse processo. Repensar esse espaço é ressignificá-lo como possibilidade de encontro da comunidade linguística, de discussão curricular, especialmente no que se refere à inclusão da criança surda na instituição de educação infantil.

Uma educação escolar bilíngue sem ser pensada e determinada a partir de um único modelo, exige mudanças contínuas para produzir alguns significados e pontuar algumas diferenças. A mudança não se reduz ao uso de língua somente.

Se uma das funções da escola é atuar nessa tensão e multiplicidade, levar em conta as diferenças combatendo a desigualdade e assegurar a apropriação do conhecimento, pois o que singulariza o ser humano social é sua pluralidade, e o que favorece superar a particularidade é o conhecimento universal, sobretudo a dimensão da história.

\section{REFERÊNCIAS}


BIESTA, G. Para além da aprendizagem: educação democrática para um futuro humano. Belo Horizonte: Autêntica editora, 2013.

BRASIL. Lei $n^{\circ} 10.436$, de 24 de abril de 2002. Diário Oficial da República Federativa do Brasil, Brasília, 25 de abril de 2002.

Decreto $n^{\circ}$ 5.626, de 22 de dezembro de 2005. Diário Oficial da República

Federativa do Brasil, Brasília, 23 de dez. 2005.

FOUCAULT, M. O governo de si e dos outros. Curso no Collège de France (1982-1983).

São Paulo: Martins Fontes, 2010.

LACERDA, C.B.F.; SANTOS, L. F. dos (Orgs.). Tenho um Aluno Surdo, e Agora?

Introdução à LIBRAS e educação de surdos. São Carlos: EduFSCar, 2013.

LARROSA, Jorge. Desejo de realidade. Experiência e alteridade na investigação educativa. In: BORBA, Siomara; KOHAN, Walter (Orgs.). Filosofia, aprendizagem e experiência. Belo Horizonte: Autêntica Editora, 2008.

LOPES, M. C. Surdez \& Educação. Belo Horizonte: Autêntica, 2007.

MASSCHELEIN, J.; SIMONS, M. A pedagogia, a democracia e a escola. Belo Horizonte: Autentica, 2014.

MASSCHELEIN, J.; SIMONS, M. A língua da escola: alienante ou emancipadora?. In: LARROSA, Jorge (Org.). Elogio da escola. Belo Horizonte: Autentica, 2017.

SOUZA, R. M. Que palavra que te falta? São Paulo: Martins Fontes, 1998.

VIEIRA-MACHADO, L. M.C; VICTOR, S.L. A criança surda: a infância na constituição de um espaço pedagógico que se ocupe da diferença. Revista Educação Especial; v. 28; n. 53, p. 623-634, set./dez. 2015.

VIEIRA-MACHADO, L. M.C.; LOPES, M. C. A constituição de uma educação bilíngue e a formação de professores de surdos. Educação \& Realidade. Porto Alegre, v. 41, n.3. p.629967, jul./set. 2016.

TEIXEIRA, Keila Cardoso. A criança surda na educação infantil: contribuições para pensar a educação bilíngue e o atendimento educacional especializado. Programa de Pós-Graduação em Educação, PPGE, UFES. Tese de doutorado, 2016, $216 \mathrm{f}$.

WITCHS, Pedro; LOPES, Maura Corcini. Surdez como matriz de experiência. INES, Revista Espaço, Rio de Janeiro, n. 43, jan./jun. 2015.

Recebido em: 09/05/2019

Aprovado em:12/07/2019 